\title{
Booktubers: Elogio da Materialidade e do Compartilhamento
}

\author{
Booktubers: praise for materiality and sharing
}

Thaís Costa da Silva

Doutoranda em Comunicação Social pela Universidade do Estado do Rio de Janeiro - PPGCOM/UERJ. Pesquisadora do Centro de Estudos Sociais Aplicados da Universidade Candido Mendes - CESAP/UCAM.

E-mail de contato: thais unirio@yahoo.com.br

\section{Maria Isabel Mendes de Almeida}

Pós-Doutora em Sociologia pela Universidade René Descartes Paris V - Sorbonne. Doutora em Sociologia pelo Instituto Universitário de Pesquisas do Rio de Janeiro IUPERJ. Coordenadora do Centro de Estudos Sociais Aplicados -CESAP/UCAM - e professora do Departamento de Ciências Sociais da PUC-Rio.

E-mail de contato: isabelmendes2008@gmail.com

\section{Lilian Alves Gomes}

Cientista Social pela Universidade Federal de Minas Gerais - UFMG, mestre e doutora em Antropologia Social pelo Museu Nacional da Universidade Federal do Rio de Janeiro - UFRJ, pesquisadora do Centro de Estudos Sociais Aplicados da Universidade Candido Mendes - CESAP/UCAM.

E-mail de contato: lilianallves@gmail.com

Submetido em 20 de Agosto de 2020

Aceito em 29 de Outubro de 2020

\section{RESUMO}

Booktubers são leitores majoritariamente jovens que se dedicam a fazer considerações sobre exemplares literários em canais do YouTube. Por meio da análise de seus vídeos, da promoção de um encontro de booktubers e da participação em outros eventos, observamos como é pungente o apreço pelos livros em papel. A ênfase em aspectos materiais dos exemplares (cores, texturas, acabamento etc.) nos possibilita percorrer dimensões do relacionamento entre livro e leitor que flertam com os trejeitos do colecionador benjaminiano. 
Diferentemente deste, contudo, os booktubers não constituem suas coleções como trincheiras e sim como janelas que nos permitem relativizar a estereotipia do jovem fechado em seu quarto.

PALAVRAS-CHAVE: Booktubers; Colecionador; Walter Benjamin; Compartilhamento; Materialidades.

\section{ABSTRACT}

Booktubers are mostly young readers who are dedicated to talk about literary works on YouTube channels. Through analyzing videos, promoting a meeting of booktubers and participating in other events, we observe how poignant the appreciation for paper books is. The emphasis on book material aspects (colors, textures, finishes, etc.) allows us to go through dimensions of relationship that flirt with the Walter Benjamin collector's mannerisms. Unlike this, booktubers do not constitute their collections as trenches, but as windows that allow us to relativize the stereotypy of the young man closed in his room.

KEYWORDS: Booktubers; Collector; Walter Benjamin; Sharing; Materialities.

\section{Introdução}

Desinteresse pela leitura, alheamento à realidade e fixação por novas tecnologias são lugares comuns facilmente atrelados aos jovens da contemporaneidade. Em consonância com a necessidade de mudar a pergunta sobre "quanto se lê" para a problemática de "como se lê" (Canclini, 2015), abordamos as práticas de leitura por meio de um amplo espectro de dispositivos, plataformas e suas variadas possibilidades de utilização. A partir dessa perspectiva, refletimos sobre o caráter híbrido e por vezes fragmentado da circulação de informações, que implica em reconfigurações do espaço íntimo hermético naturalizado como lócus da experiência de leitura.

Interessa-nos tematizar como o acesso a tempos e a espaços outros, propiciado por essa experiência, é atravessado pelo desejo de encontro e de compartilhamento com outros leitores, o que é impulsionado através de plataformas virtuais como o YouTube. Os interlocutores de tal reflexão são

\section{Dossiê Crise, Feminismo e Comunicação - https://revistaecopos.eco.ufrj.br/}

ISSN 2175-8689 - v. 23, n. 3, 2020

DOI: 10.29146/eco-pos.v23i3.27580 
booktubers, jovens que em nada se assemelham ao estereótipo do leitor solitário e antissocial refugiado em um espaço íntimo, como o quarto. ${ }^{1}$

Roger Chartier (1999) advoga pela dissolução do postulado de um leitor universal e nos lembra que escritores não escrevem livros, mas textos que passam por estratégias de edição, impressão e produção material, que, por sua vez, atuam na relação do leitor com o texto escrito. 0 referencial desse autor tornou-se nevrálgico para a história da leitura, dada a importância dirigida às modalidades de publicação, disseminação e apropriação dos textos. Entretanto, como afirmou o próprio historiador francês (Chartier, 2018), as circunstâncias e as modalidades concretas do ato de ler na contemporaneidade ainda são pouco exploradas.

O desenvolvimento tecnológico que possibilitou a proliferação de dispositivos, ferramentas e suportes que tanto contribuíram para complexificar os modos de leitura não ocasionou o fim dos livros em papel, como muitos previam (Eco, Carrière, 2010). Estamos diante de uma revolução nos modos de leitura (Darnton, 1987), que nos demanda um processo de adaptação muito grande frente às novas possibilidades de ler (IS, 2020).

A leitura silenciosa e de foro privado, como nos lembra De Certeau (2008, p. 271), é uma experiência "moderna". 0 acesso aos textos, por muito tempo, podia se dar a partir da presença de alguém que lia para os outros. A prática de leitura individual, valendo-se apenas da mobilidade dos olhos e não mais da voz, por sua vez, emancipou o gesto de ler da arena pública. Contudo, é sabido que pessoas continuaram a ler para outras, seja para aquelas que não sabem decifrar textos, como as crianças, seja para "cimentar as formas de sociabilidade em espaços comunitários" (Santaella, 2004, p. 22).

A performance oral concernente às práticas de leitura, nesse sentido, não diz respeito apenas a períodos históricos circunscritos. Nos dias atuais a propagação do texto pela voz - seja pela leitura direta ou por comentários e

\footnotetext{
${ }^{1}$ Os booktubers se inserem em um escopo mais amplo de jovens leitores com quem estabelecemos interlocução no âmbito do projeto Territórios Literários: novas tecnologias, práticas de leitura e de compartilhamento na contemporaneidade, conduzido entre 2016 e 2019.
}

Dossiê Crise, Feminismo e Comunicação - https://revistaecopos.eco.ufrj.br/

ISSN 2175-8689 - v. 23, n. 3, 2020

DOI: 10.29146/eco-pos.v23i3.27580 
conversas sobre o ato de ler - mobiliza clubes de leitura, saraus e, no âmbito da internet, o booktube, comunidade online sobre a qual refletimos aqui e que tem o livro como pauta principal.

Formada majoritariamente por jovens, a comunidade tem como figuras de destaque os booktubers, que se dedicam a apresentar vídeos com considerações sobre exemplares literários no YouTube. Por meio da análise de seus vídeos, da promoção de um encontro de booktubers e da participação em seus eventos, buscamos compreender o apreço pelos livros em papel. Enfocamos a comunicação de aspectos sobre a sociabilidade em torno das obras, bastante pautada pela sensorialidade.

Considerando a ênfase sobre aspectos materiais dos livros (cores, texturas, acabamento etc.), destacamos como as dimensões de relacionamento da comunidade flertam com os trejeitos do colecionador benjaminiano. Em seguida, abordamos como o compartilhamento de comentários sobre livros na internet fomenta encontros e celebrações face a face. Discutimos ainda como a atuação dos booktubers incide em reconfigurações do mercado literário, em especial quando a produção de conteúdo desses sujeitos criativos é visada por editoras. Por fim, sublinhamos aspectos sobre leitura e interioridade que retomam algumas reflexões chave do texto.

\section{0 livro perante as telas}

Os booktubers falam sobre livros, leitura e assuntos correlatos para os inscritos e demais pessoas que assistem a seus canais. Dando uma nova roupagem aos antigos vlogs de leitura, feitos com ferramentas tecnológicas mais limitadas, eles têm seguido cada vez mais um padrão profissional na produção de conteúdo, como iluminação adequada, cenário cativante e bons equipamentos de filmagem. Nesse sentido, corroboram a frequente associação entre jovens e uso das tecnologias mais recentes.

\section{Dossiê Crise, Feminismo e Comunicação - https://revistaecopos.eco.ufrj.br/}

ISSN 2175-8689 - v. 23, n. 3, 2020

DOI: 10.29146/eco-pos.v23i3.27580 
Por outro lado, é interessante notar que esses produtores de conteúdo se valem dos traquejos na lida com o domínio digital para publicizar a paixão por um objeto analógico. Os suportes digitais de leitura, como o e-reader e os audiolivros, também se fazem presentes nas rotinas de muitos booktubers, mas ocupam um lugar coadjuvante nos vídeos². Do cheiro peculiar das páginas à estética das capas, certas características dos livros em papel - para além e em forte diálogo com as histórias que portam - encantam e garantem a presença desses objetos como motes dos vídeos que analisamos.

As postagens de booktubers não estão entre os segmentos que mais atraem público no YouTube, mas conseguem manter uma rede forte e bastante participativa. Os mais populares no Brasil reúnem um público de cerca de 300 a 400 mil inscritos, com exceção de Bel Rodrigues, que em 2019 alcançou a marca de 700 mil inscritos. Em muitos dos vídeos feitos pela booktuber, o livro é o protagonista, seja ele exposto na estante que adorna o cenário, seja envolvido em demonstração de intensa afetividade com carícias e beijos ou, ainda, em discussões sobre o enredo.

A materialidade do livro pode chegar a ser até mais importante do que seu conteúdo literário. 0 culto a essa forma se volta principalmente ao elemento capa, em geral a parte mais admirada do objeto. Suas cores, texturas, o tipo de material utilizado, o formato, as imagens que lhe dão destaque, tudo é importante e compõe a obra. E, neste sentido, afloram ações que ressaltam aspectos sensoriais envolvidos nos gestos de leitura, como cheirar o livro e sentir a textura do papel.

\footnotetext{
2 Comentários sobre conteúdo lido em leitores digitais vêm à baila quando o livro em papel não pode ser acessado, como quando o booktuber deseja ler algo ainda não publicado sob a forma impressa no Brasil ou quando é instado por um clube de leitura a ler um título e precisa acessá-lo em tempo hábil para a discussão do enredo com os integrantes do clube. Os dispositivos que possibilitam a leitura nas telas também são temas de vídeo, como será visto adiante.
}

Dossiê Crise, Feminismo e Comunicação - https://revistaecopos.eco.ufrj.br/

ISSN 2175-8689 - v. 23, n. 3, 2020

DOI: 10.29146/eco-pos.v23i3.27580 
“Gente, essa capa aqui é maravilhosa né? Eu comprei [o livro] por causa dela". Com muito entusiasmo, Melina Souza, do canal homônimo no YouTube, apresenta - e acaricia -um de seus livros no vídeo "Book Haul”3.

Acompanhamos mais de dez canais ao longo da pesquisa e, em todos, encontramos variações dessa cena. Os aspectos materiais do livro são destacados como motivadores do consumo do objeto, que pode ser utilizado tanto como adorno quanto como suporte de leitura.

Isso não significa que os booktubers não leiam o conteúdo dos livros. Muitos discorrem sobre as histórias após enaltecerem as capas. A estética funciona como incitação à leitura: a relação entre a materialidade e o conteúdo literário é muito pungente. A parte externa pode indicar algo sobre a história contida em seu interior e ensejar interpretações diversas. Beatriz Paludetto, no vídeo "A Verdade sobre o Booktube com GeekFreak"4, ao discorrer sobre como a prática de ler muitos livros a afeta, revela que consegue perceber se o livro vai agradá-la ou não de acordo com a sua exterioridade. "Você já tem aquele radar ali! Só olhar a capa e falar 'é esse aí que eu vou gostar, esse aqui não'...".

A capa, assim, assume grande importância por seu potencial motivador de compra do livro. Ela é a exterioridade do artefato, no que Gell (2001) chamaria de "armadilha", quando discorre sobre objetos artísticos (e outros com poder de atração). Trata-se de uma captura da atenção do leitor, convidado a conhecer o interior do livro a partir da capa. Ela pode ser considerada uma "representação transformada", que, por sua materialidade, estabelece uma comunicação entre o objeto e o sujeito a ser capturado - o caçador e a caça -, promovendo a ideia de um "nexo de intencionalidades" entre eles. A sedução material se expressa nas vitrines das livrarias e nos próprios vídeos dos booktubers.

3 YouTube. Melina Souza. Book Haul. (2016, Agosto 04). Disponível em: https://www.youtube.com/watch?v=swZ2ybUUJEk. Acesso em: 10 de dezembro de 2019.

4 YouTube. Beatriz Paludetto. A Verdade sobre o Booktube com Geek Freak: Patrocínio, editoras e fofocas. (2019, Novembro 18). Disponível em: https://www.youtube.com/watch?v=w7QRNOwKdts. Acesso em: 10 de dezembro de 2019.

Dossiê Crise, Feminismo e Comunicação - https://revistaecopos.eco.ufrj.br/

ISSN 2175-8689 - v. 23, n. 3, 2020

DOI: 10.29146/eco-pos.v23i3.27580 
Na série BookShelf Tour, ou "passeio pela estante de livros", em português, os booktubers apresentam os exemplares enquanto explicam como cuidam de suas bibliotecas particulares. São diversas as possibilidades de organização, assim como nas livrarias e bibliotecas: por autor, tamanho, título, cor etc. As características físicas, mais uma vez, ganham destaque nos vídeos, e o zelo com os exemplares, para que eles não amassem, rasguem ou se deteriorem, corroboram o apreço pela materialidade.

Alguns elementos são conectados de modo a manter a construção de um enredo em cada passeio pelas estantes. "Um livro chama o outro, antecedente ou posterior, movimento infinito no qual o saber se desordena, no qual o fantasmático opera" (Pic, 2015, p. 70). As ligações entre esses livros acionam o íntimo, as memórias e os gostos, que são exteriorizados frente à câmera. Dessa forma, o conteúdo das estantes extrapola a esfera do privado, assim como muitas vivências relativas aos livros exibidos.

Willine Gabriele, do canal homônimo, explica um pouco sua relação com os livros e reforça a importância da existência física deles, especialmente ao discorrer sobre os três exemplares de sua coleção da saga Crepúsculo. No vídeo "Bookshelf Tour"5 ela explica: "Aí eu tenho esses três aqui que são com a capa do filme, que são muito lindas. Eu comprei porque estavam os três juntos por dez reais. Eu achei tão linda que eu comprei, pra ficar só de enfeite mesmo". Neste caso, os livros assumem um lugar de adorno, compondo a coleção de livros expostos na estante, e indicam as preferências e gostos culturais da booktuber, ao destacar a produção transmidiática Crepúsculo.

Muitos booktubers, dessa forma, adquirem diferentes edições em que a diagramação, a arte da capa, o tipo de papel utilizado ou o formato chamem a atenção deles de alguma forma. Conforme Willine expõe, existem edições comemorativas ou com capas de iconografia baseada nos cartazes das produções

5 YouTube. Willine Gabriele. Bookshelf Tour 2016: Tour pelos meus livros! (2016, Maio 28). Disponível em: https://www.youtube.com/watch?v=T44rXboPsTY

Dossiê Crise, Feminismo e Comunicação - https://revistaecopos.eco.ufrj.br/

ISSN 2175-8689 - v. 23, n. 3, 2020

DOI: 10.29146/eco-pos.v23i3.27580 
cinematográficas correspondentes, ressaltando o fenômeno da convergência (Jenkins, 2008), em que as produções culturais buscam se desenvolver em diversos ambientes midiáticos, como filmes e livros.

Essa forma de consumo afinada com lançamentos recentes da indústria cultural paradoxalmente nos coloca na presença de um sujeito cuja emergência está atrelada à crítica do progresso capitalista: o colecionador benjaminiano. Para Benjamin (2006), cultivar uma coleção é um modo de construir trincheira contra o universo moderno desencantado (Gomes, 2019). Nessa trincheira, os objetos são destituídos do caráter de mercadoria e da obrigação de serem úteis. Um colecionador de livros dificilmente lê todo o seu acervo, assim com um colecionador de porcelanas não as utiliza cotidianamente. Ademais, para Benjamin (2006, p. 241), a relação do colecionador com suas coisas é permeada de "instinto prático", cuja posse permite o aprimoramento: "possuir e ter estão relacionados ao caráter tátil e se opõem em certa medida à percepção visual. Colecionadores são pessoas com instinto tátil."

O desejo de posse motivado pela forma da obra, nesse sentido, evidencia outras funcionalidades do livro para além da recepção e apreensão do conteúdo textual. É possível entender esse ato de colecionar livros como algo que contribui para a construção de subjetividade, na medida em que o booktuber explicita para os seguidores do canal suas preferências, estilos de leitura e consumo cultural.

O juízo estético e a qualidade dos materiais utilizados nas edições, ou seja, interioridade e exterioridade, são merecedores de avaliações e críticas. Nessa direção, Eduardo Cilto, do canal Perdido nos Livros, dedica quatro minutos em cada um dos dois vídeos, "Capas mais bonitas da minha estante"6 e "Capas mais feias da minha estante"7, para comentar a aparência de alguns de seus livros. A narração

\footnotetext{
${ }^{6}$ YouTube. Eduardo Cilto. Capas mais bonitas da minha estante (2015, Agosto, 3).

Disponível em: https://www.youtube.com/watch?v=cbWkMlwTdpk. Acesso em: 10 de dezembro de 2019.

7 YouTube. Eduardo Cilto. Capas mais feias da minha estante (2015, Setembro, 28). Disponível em: https://www.youtube.com/watch?v=sZKI9U1ecFI. Acesso em: 10 de dezembro de 2019.
}

Dossiê Crise, Feminismo e Comunicação - https://revistaecopos.eco.ufrj.br/

ISSN 2175-8689 - v. 23, n. 3, 2020

DOI: 10.29146/eco-pos.v23i3.27580 
das reações sensoriais estimula novos gestos, como beijos e afagos. 0 booktuber se diz "apaixonado" ao falar de suas capas favoritas e não deixa de mostrar que também possui livros "horrorosos", "horríveis". Em ambos os vídeos, é perceptível quanto de sua admiração pelos livros revela um envolvimento não somente com o conteúdo literário, mas com a materialidade dos exemplares. Em sua avaliação do livro Adeus, por enquanto, Eduardo conta tê-lo adquirido somente pela capa:

Esse próximo livro [“Adeus, por enquanto"] eu só comprei pela capa, porque eu vi lá na livraria e disse 'Meu Deus, eu preciso desse livro, eu preciso comprar'. Julguei pela capa mesmo e dane-se essa história aí. (...) A capa é incrível. Toda vez que eu quero referência de design, eu lembro dessa capa. Porque eu acho muito, muito, muito bonita (informação verbal).

A materialidade pode ainda marcar os usos que se faz do livro e, de certa forma, perpetuar sensações dos momentos da leitura. No vídeo "Os Livros Mais Especiais da Minha Estante: Favoritos, Raridades e Queridos"8, Beatriz Paludetto menciona as marcas em seu livro mais antigo da saga Crepúsculo: "E aí tem marcas de lágrimas nesse, quando o Edward deixa a Bela e, ai, eu chorei muito nesse livro gente. Ele tem muitas marcas de usado, sabe? Eu acho isso muito legal, porque ele é bem antigo."

Existem formas múltiplas de envolvimento com o objeto da coleção, que afeta cada um por razões singulares. Retornando à figura do colecionador benjaminiano, o mais importante de todo exemplar é o encontro que ele promove entre o colecionador e partes integrantes e fundamentais de sua própria coleção. 0 livro nunca se encerra em si mesmo, se estendendo para além de sua condição objetiva. Há uma pulsação maior que se estabelece e extrapola a simples aquisição. A subjetividade, nesse sentido, é elaborada na inserção dos livros em estantes sempre inacabadas, que revelam um pouco das pessoas que as expõem nos vídeos.

\footnotetext{
8 YouTube. Beatriz Paludetto. Os Livros Mais Especiais da Minha Estante: Favoritos, Raridades e Queridos (2019, Novembro, 29). Disponível em: https://www.youtube.com/watch?v=1n6yoOH9. Acesso em: 10 de dezembro de 2019.
}

Dossiê Crise, Feminismo e Comunicação - https://revistaecopos.eco.ufrj.br/

ISSN 2175-8689 - v. 23, n. 3, 2020

DOI: 10.29146/eco-pos.v23i3.27580 
A "tensão dialética" entre os pólos da ordem e da desordem exprime-se na ordenação de uma biblioteca. No caso dos booktubers, eles fazem questão de publicizar essas contraposições. Na prática, a única contrapartida da desordem é a ordenação de seu catálogo. "Nesse domínio, toda ordem é precisamente uma situação oscilante à beira do precipício" (Benjamin, 1987, p. 228). Considerando que muitos booktubers frequentemente ganham, compram e trocam livros, essas bibliotecas seguem em constante atualização e (des)organização.

A partir das resenhas publicadas, a contemplação dos livros e o prazer da posse são compartilhados entre booktubers e seguidores. Na prática do Bookshelf Tour, as aquisições são orgulhosamente exibidas, em especial as tidas como bonitas e vistosas. Muitos preferem dividir sua coleção por cores, o que contribui para um cenário ainda mais atraente no vídeo. 0 plano de fundo é composto por livros, pôsteres e bonecos decorativos (action figures), referências a personagens de livros e filmes da cultura pop. 0 passeio pela estante é acompanhado da narração de histórias sobre como os exemplares foram adquiridos e de que forma eles participam da vida dos jovens leitores.

O cheiro, o tipo de lombada, a visualidade da capa, as texturas e os formatos, as possibilidades de manuseio, enfim, certa palpabilidade dos livros em papel agrada aos leitores de tal maneira que esse dispositivo se mantém ainda como o mais vendido frente aos livros digitais, que alcançam um percentual de faturamento de apenas 1,09\%, conforme resultados do último Censo do Livro Digital $^{9}$. Assim, os livros digitais se apresentam como complementares, de acordo com as diferentes ocasiões e necessidades. Darnton (1987) nos conta sobre a coexistência de suportes e formatos: códex/rolos, textos impressos/rolos e agora livros em papel/livros digitais. A procura pelo livro em papel permanece entre os leitores contemporâneos, que transitam entre múltiplas possibilidades.

\footnotetext{
${ }^{9}$ Censo do Livro Digital. Pesquisa realizada pela Câmara Brasileira do Livro, pelo Sindicato Nacional dos Editores de Livros e pela Fundação Instituto de Pesquisas Econômicas, em 2016. Disponível em: https://snel.org.br/wp/wp-content/uploads/2018/02/Apresentacao-Censo-do-Livro-Digital.pdf.
}

Dossiê Crise, Feminismo e Comunicação - https://revistaecopos.eco.ufrj.br/

ISSN 2175-8689 - v. 23, n. 3, 2020

DOI: 10.29146/eco-pos.v23i3.27580 
Essa realidade reforça o caráter híbrido das práticas de leitura contemporâneas e também incide nos modos de ler e de interpretar textos. A multiplicidade dos artefatos textuais, como imagens, marcas, partituras, diagramação, interfere na qualificação, recepção e compreensão dos textos (McKenzie, 2004). Podemos considerar, assim, que o texto disponível em formato de livro impresso é diferente daquele em formato digital, visto que este último possui elementos textuais díspares, como a própria linguagem de hiperlinks, que permite a navegação entre diferentes conteúdos. 0 leitor das telas é também o do papel, ainda que possa haver preferências entre uma e outra modalidade. Por essa razão, os booktubers comentam também sobre os e-books e leitores digitais, apresentando, inclusive, os prós e os contras de cada um, de acordo com suas experiências e perfis.

\section{0 compartilhamento e o desejo do encontro}

Diferentemente da reflexão benjaminiana, que pressupõe a interioridade do colecionador, a figura do booktuber se insere em uma lógica do compartilhamento e em uma cultura da participação, comportamentos muito estimados na contemporaneidade, como apontado por Shirky (2011) e Jenkins (2008). Com os estímulos produzidos pelas novas tecnologias da comunicação e informação, conectar-se a um grande fluxo de pessoas e informações pode estar ao alcance de muitos, assim como produzir e consumir coletivamente, ainda que haja muitas desigualdades e assimetrias nesses processos e relações. É também a partir da própria coleção que os jovens leitores booktubers acessam o mundo. Não somente pelo conteúdo dos livros em si, que os leva para outros mundos, mas pela oportunidade de dividir suas experiências de leitura com outras pessoas, sem que precisem sair das imediações de seus quartos.

É nesse espaço, à primeira vista íntimo e fechado, que suas ações se desenham, na maioria dos casos. Os booktubers gravam os vídeos e os transmitem

\section{Dossiê Crise, Feminismo e Comunicação - https://revistaecopos.eco.ufri.br/}

ISSN $2175-8689$ - v. 23, n. 3, 2020

DOI: 10.29146/eco-pos.v23i3.27580 
para uma quantidade variável de pessoas, seguidores ou não, em uma rede aberta e global - a internet. Habitados por dimensões simbólicas e significações sociais distintas, os espaços do quarto e da internet se valem de representações coletivas opostas, com regras, leis e normas particulares, opondo o caráter público ao privado. Mas, ao transitar entre essas duas esferas sociais, o booktuber cria um novo espaço a partir da leitura, nem totalmente público, nem totalmente privado.

Nas "maratonas literárias", os booktubers passam horas lendo e apresentando o processo em tempo real aos seguidores. Nesses vídeos, eles contam suas preferências de leitura, bem como as relações entre o que é lido e suas características pessoais, os lugares onde eles mais gostam de ler, entre outros aspectos do íntimo performado que se expõe ao público. Assim fazem-se notar as transformações nas subjetividades contemporâneas a partir das narrações e publicização da intimidade (Sibilia, 2016).

Como Sennett (1999), a autora enfatiza as influências do capitalismo para esse movimento, com seus dispositivos de poder que capturam vestígios de criatividade bem-sucedida com vistas a transformá-los em mercadoria. Nessa esfera, há um contraponto entre a solidão e o silêncio do quarto - que permitiam o diálogo com a própria interioridade em séculos passados - e a exibição do privado na esfera pública da internet nos tempos atuais. Se o que era considerado real antes precisava estar no livro, hoje, para existir, é preciso estar na tela.

Assim, o jovem leitor integrante dessa comunidade, seja ele um booktuber ou parte da audiência, se distancia da representação solitária que pode ser concebida quando nos referimos aos jovens reclusos no quarto, microcosmo propício não só para leitura como para o devaneio, para a meditação, enfim, para a guarda de alguma autonomia em relação ao que se passa no entorno. Não descartarmos as consequências nefastas da hiperconexão na sociabilidade (Almeida, 2020). No entanto, gostaríamos de insistir que, a despeito das diversas assimetrias e capturas do capitalismo em relação ao partilhar nas redes, 
observamos também singulares tessituras coletivas ensejadas pelo apreço aos livros.

Desse modo, ao invés de sublinharmos o reiterado culto à autoimagem presente nas redes sociais online, destacamos práticas de leitura que mobilizam modos de estar e de produzir junto, entre conhecidos e estranhos que partilham informações na comunidade booktube. 0 aparente distanciamento propiciado pelas telas na sociedade contemporânea permite outros tipos de interação e de socialização que extrapolam a necessidade da presença física, embora ela ainda possa acontecer com muita frequência. São configurações contemporâneas de relações sociais que ampliam os espaços de convivência, mediados ou não por tecnologias digitais.

O compartilhamento de ações e emoções é percebido como nova maneira de estar no mundo, pautada por construções de si que são orientadas para o olhar alheio (Sibilia, 2016). Daí o cuidado com a produção do cenário, com a qualidade do vídeo e com a imagem daquele que está de frente para a câmera. Tudo isso constitui um cenário íntimo cuidadosamente pensado para ser exposto, já que é desse conteúdo que partirão muitas das interações.

As dinâmicas da rede fluem então a partir dos vídeos dos booktubers. Mas seus seguidores também contribuem para o conteúdo do canal, por meio de comentários, curtidas e compartilhamentos dos vídeos em outras mídias sociais, ações que mantêm a comunidade ativa e plural. Os seguidores são prosumidores, (do inglês, prosumer), classe de consumidores que participam também do processo produtivo (Toffler, 2007), que expressam suas opiniões sobre o tema do vídeo e sugerem novas temáticas a serem tratadas, em uma lógica colaborativa.

Na seção de comentários do vídeo "Fim de ano Book Tag"10, do canal Livros e Fuxicos, de Paola Aleksandra, de apelido Pah, Isabelli comentou: "Pah faz mais vídeos em sebo eu amo!!!", indicando que gostaria de ver o tema citado com mais

10 YouTube. Paola Aleksandra. Fim de ano Book Tag, Livros e Fuxicos (2019, Dezembro 9). Disponível em: https://www.youtube.com/watch?v=A9Jnyz6oxVA. Acesso em: 10 de dezembro de 2019.

Dossiê Crise, Feminismo e Comunicação - https://revistaecopos.eco.ufrj.br/

ISSN 2175-8689 - v. 23, n. 3, 2020

DOI: 10.29146/eco-pos.v23i3.27580 
freqüência no referido canal. E também Cíntia, corroborando a ideia levantada pela booktuber sobre realizar um projeto de leitura de fantasia: "Faz o projeto de fantasia que quero participar. Tão feliz que finalmente você vai ler Pollyana. Finalmente!!!”

Há, ainda, o fortalecimento de conexões entre seguidores, seguidores e booktubers ou entre booktubers. Aproximações que compõem essa rede altamente mutável e ativa. Alguns comentários incitam conversas relacionadas ao assunto do vídeo entre os integrantes da comunidade, como o de Max na página do vídeo "Tudo sobre o Kindle, vale mesmo a pena"11, do canal de Bel Rodrigues: "Comprei meu Kindle na blackfriday do ano passado e foi a melhor compra que fiz na vida. $<3$ ". O depoimento do seguidor do canal obteve dezesseis respostas, no momento da coleta de dados, formando uma pequena discussão sobre o assunto levantado. Alguns perguntavam sobre o preço do dispositivo de leitura Kindle, outros respondiam sobre o valor, alguns somente concordavam com o comentário, outros questionavam sobre as características do aparelho, configurando ramificações diversas das interações online sobre leitura.

A grande repercussão dos vídeos produzidos a partir de tags já denota algumas das possibilidades de conexão dessa rede. Cada booktuber, ao fazer o seu vídeo e responder às perguntas concernentes ao tema indicado, convida outro colega para fazer o mesmo. Os temas são variados, como "Hábitos de Leitura" ou tags com perguntas sobre o universo de alguma trama, como a "Gilmore Girls Book Tag”, inspirada em uma série de plataforma streaming. Nos comentários, os seguidores também podem responder às perguntas e indicar outras pessoas. São "correntes" temáticas para incluir um número maior de pessoas e ajudar na produção de conteúdo dos canais.

As interações em torno da leitura também se desenvolvem em outras mídias, como blogs, Instagram, Twitter e Facebook. Essa variedade de plataformas

11 YouTube. Bel Rodrigues. Tudo Sobre 0 Kindle: Vale mesmo a pena? (2019, Março 27). Disponível em: https://www.youtube.com/watch?v=eFqHq5IP-uo. Acesso em: 10 de dezembro de 2019.

Dossiê Crise, Feminismo e Comunicação - https://revistaecopos.eco.ufrj.br/

ISSN 2175-8689 - v. 23, n. 3, 2020

DOI: 10.29146/eco-pos.v23i3.27580 
amplia as possibilidades de conexão e acesso ao conteúdo produzido coletivamente. Isso porque tanto os booktubers quanto os seguidores alimentam essa rede com reações diversas em um fluxo intenso. Além disso, muitos desses jovens são também escritores e produzem conteúdo textual também para a sua rede, como é o caso de Bel Rodrigues.

As interações se engendram de variadas maneiras, por diversos canais e suportes. 0 tipo de linguagem, os temas abordados e os enfoques se diferenciam de acordo com a mídia em questão. Para cada uma delas, há uma estratégia de ação, sem que se distancie do tema da leitura: elementos que não se caracterizam somente como mediadores das interlocuções, mas como agentes na produção de sentidos na rede.

Mesmo com tantas possibilidades de conexão online, a comunidade booktube busca também promover encontros coletivos presenciais. Sejam organizadas em eventos literários de terceiros ou promovidas pelos próprios booktubers, essas atividades surgem de um desejo coletivo do encontro face a face que vai além das telas, provocando a saída dos quartos para os espaços da cidade. Esse movimento vai de encontro a muitas teses (Turkle, 2011), (Sennet, 2012), (Crary, 2014) que defendem que o uso excessivo das novas tecnologias da comunicação e informação leva ao isolamento e ao atrofiamento das relações intersubjetivas face a face.

Os booktubers e os jovens que os assistem não estão sós, ainda que o teor e a intensidade das relações possam variar. Também é importante considerar as condicionantes socioeconômicas dessa comunidade, formada por pessoas que possuem recursos financeiros e habilidades técnicas e cognitivas para o acesso e o uso das plataformas e dispositivos tecnológicos. Contudo, as tecnologias não os têm apartado; apenas reconfiguram formas de interação.

Os encontros mantêm como fio condutor a temática literária. Assim, são organizados clubes de leitura, rodas de conversa ou mesmo brincadeiras de amigo secreto em que os presentes trocados são necessariamente livros. O Clube de 
Leitura de Duque de Caxias, por exemplo, fundado pelos booktubers Kelly Cominoti, do canal Aventuras na leitura, e Alexsander Costa, do canal Um Bookaholic, mensalmente reúne jovens interessados em leitura na biblioteca pública central da cidade. A cada encontro, uma discussão sobre um livro diferente previamente escolhido por meio de votação. Para a seleção, os gêneros literários variam, assim como os autores, para se diversificar as temáticas das conversas ${ }^{12}$.

Na sessão temática de Halloween de que participamos, em outubro de 2016, compareceram quatorze jovens, com idade entre dezesseis e vinte e cinco anos. 0 nível de entrosamento entre eles demonstrava os vínculos de amizade. Alguns já se conheciam, enquanto outros começaram a se relacionar quando entraram para o clube. Em homenagem ao dia das bruxas, a discussão foi sobre contos do romancista estadunidense Edgar Allan Poe, conhecido por suas histórias misteriosas e macabras. 0 acordo estabelecido foi que cada participante poderia ler o(s) conto(s) que quisesse para narrar suas impressões.

Inicialmente foram feitos comentários sobre o autor, que desencadearam discussões sobre as histórias. 0 tom da conversa era informal, e o alvoroço em torno dos contos se reforçava pelo ensejo do encontro com os demais. 0 evento era também uma forma de trocar experiências de leitura, ressaltar os aspectos dos contos que intrigaram os leitores e até mesmo expor algumas lamentações sobre não conseguirem ler tanto quanto gostariam em função do pouco tempo disponível para essa atividade (tipo de lamento observável em incontáveis vídeos de booktubers).

Após as discussões sobre leitura, os participantes conversaram sobre outros assuntos e desfrutaram de um lanche organizado em conjunto. Em tom de festa, com decoração temática e fotos, celebraram o fato de estarem juntos mais

12 No encontro de booktubers que promovemos, Kelly Cominoti contou que a inspiração para a criação do clube de leitura veio de uma iniciativa, bastante capilarizada no Brasil, que mobiliza a leitura de livros escritos por mulheres por meio da hashtag \#leiamulheres. Outras campanhas mobilizadas por hashtags, como \#leiaautoresnegros, evidenciam a associação contemporânea entre o gesto de ler e o compartilhamento em redes sociais digitais (Almeida, 2020).

\section{Dossiê Crise, Feminismo e Comunicação - https://revistaecopos.eco.ufrj.br/}

ISSN 2175-8689 - v. 23, n. 3, 2020

DOI: 10.29146/eco-pos.v23i3.27580 
uma vez. A comunicação entre eles, posteriormente, aconteceu de forma online, em especial pelo Facebook, onde são realizadas as enquetes para a escolha do livro do mês seguinte, entre outras discussões sobre leitura.

Também estivemos presentes em um encontro de outro grupo de booktubers e seu público, com dezoito jovens na faixa dos vinte anos, realizado no shopping Nova América, Rio de Janeiro, em julho de 2016. Muitos eram booktubers que convidaram suas respectivas audiências. A organização foi motivada pela vinda recente ao Brasil do booktuber Murilo Artese, que no período morava nos Estados Unidos. Na praça de alimentação, conversas sobre leitura se misturavam a diálogos sobre diversos outros assuntos.

A leitura estimulou debates sobre o cotidiano, incluindo, principalmente, experiências com os respectivos canais de YouTube. E, como usuários bastante ativos das ferramentas digitais, os booktubers aproveitaram o momento para narrar, registrar e divulgar o evento para o público que não estava lá. Foram muitos os vídeos gravados durante o encontro, vários deles exibidos simultaneamente nas redes sociais. Diversas fotos também foram tiradas e publicadas poucos minutos depois nas redes online.

Todo o frenesi que guiava o evento se relacionava mais uma vez ao desejo de estar junto também presencialmente: a aproximação daqueles jovens entre si era resultante de uma paixão em comum, a leitura. Apesar de os primeiros contatos terem ocorrido no ambiente digital, é notório que os laços se fortaleceram quando as pessoas se reuniram fisicamente. Muitas nunca tinham se visto pessoalmente e partilhavam da alegria que o encontro proporcionava. A troca de marcadores de livros personalizados dos canais, os abraços, as fotos do grupo, os vídeos realizados em conjunto, todos esses gestos foram motivo de grande excitação por parte dos presentes.

Mesmo quando o encontro não é exclusivo da comunidade, a agitação permanece. Durante a Bienal do Livro de 2017, no Rio de Janeiro, foi realizada uma mesa de debates entre booktubers e apreciadores da temática, intitulada "60 
encontro de Booktubers para inscritos", organizada pela empresa Amazon. Os palestrantes eram Tatiany Leite, do canal Vá ler um livro, Paulo Ratz, do Livraria em casa, e Bruna Miranda, do canal homônimo. Eram tantos os interessados que todas as cadeiras foram ocupadas, além de haver muitas pessoas de pé. Os participantes discutiram sobre aspectos que envolvem a comunidade, como a produção dos vídeos e os hábitos de leitura.

Para eles, há diferenças que marcam a comunidade booktube perante as demais do YouTube, a saber, o tipo e o nível de interação com os inscritos. 0 "engajamento" nos canais sobre livros é muito recorrente, e os comentários em geral são extensos, pois as pessoas registram suas opiniões sobre os livros discutidos, como salientado por Paulo Ratz. A paixão compartilhada pelo livro se mostra nos famosos "textões" dos comentários no YouTube e em outras redes, assim como em encontros presenciais, onde há oportunidade para um contato mais próximo.

Para os jovens leitores booktubers e seus seguidores, o livro é uma festa. Nos diversos encontros que acompanhamos, cada qual com suas características e especificidades, que variavam de acordo com os grupos envolvidos, foi possível notar o caráter de celebração. A dimensão situacional do encontro, impulsionada e guiada pelo gosto pela leitura, evidencia a peculiaridade dessa rede. Apesar dos eventuais conflitos e dissonâncias inerentes a qualquer "comunidade" - quando vista de perto e de forma não romantizada -, a rede se mantém com fortes vínculos que ultrapassam os limites das telas e das paredes dos quartos.

\section{Reconfigurações no mercado literário}

As relações estabelecidas entre os booktubers e sua audiência são intensas. O sentimento de confiança é bastante significativo e até mesmo norteador do convívio. As opiniões e informações transmitidas, a indicação de determinadas leituras e o perfil de leitor dos booktubers são fatores muito valorizados por quem

Dossiê Crise, Feminismo e Comunicação - https://revistaecopos.eco.ufri.br/

ISSN $2175-8689$ - v. 23, n. 3, 2020

DOI: 10.29146/eco-pos.v23i3.27580 
os segue. Isso os torna influenciadores digitais, termo que vem ganhando destaque na atualidade e que indica o prestígio que certas pessoas têm em função do conteúdo que geram online.

Percebendo a visibilidade dos booktubers e a intensa aproximação com seu público, muitas editoras e autores começaram a se interessar em estabelecer parcerias e negociar contratos com os jovens produtores de conteúdos. São doações de livros, de leitores digitais e até mesmo o pagamento direto a esses influenciadores para impulsionar determinadas postagens. Dependendo do tipo de acordo firmado, o booktuber faz uma resenha sobre o livro, narrando suas impressões, que podem ser positivas ou negativas.

Nos vídeos de unboxing, em que os booktubers apresentam os livros recebidos pelas editoras, há uma publicização de determinadas produções desde a abertura dos pacotes endereçados a eles. Seguindo este viés, uma das tags aderidas pela maioria deles se chama book haul. Nela, é feita a exibição também de livros trocados, comprados ou que eles ganharam de presente de pessoas conhecidas. A princípio, os booktubers não fazem o relato de opiniões sobre as histórias, já que se referem a aquisições recentes, mas comentam o tema central de cada livro e, notadamente, as características materiais dos exemplares. Em geral, os seguidores que já leram os livros expõem suas impressões sobre eles.

Essa dinâmica de mostrar os "recebidos", ou seja, presentes nem sempre abertamente tratados como patrocínios, é uma prática bastante comum na internet, envolvendo influenciadores digitais de variados segmentos, como moda, viagens, alimentação saudável, entre outros. Como atuam em plataformas de grande audiência, os influenciadores conseguem alavancar, por vezes, uma quantidade significativa de seguidores, que se interessam por suas postagens e ideias. Tendo em vista que nem sempre se trata de profissionais formados nas respectivas áreas de atuação, essa mercantilização da informação repassada pode impulsionar conflitos com distintas associações de classe. 
No caso dos influenciadores de livros, apesar de não se intitularem críticos literários, o tipo de "parceria" estabelecida com algumas editoras vem impactando o trabalho de jornalistas culturais que se dedicam a comentar sobre literatura, especialmente no que tange à remuneração dessa atividade. A horizontalidade presente na proposta de "leitores falando com outros leitores, sugerindo e criticando leituras, de igual para igual" (Jeffman, 2015, p. 106) é balançada quando os booktubers são pagos ou generosamente presenteados.

Ao contratar um booktuber no lugar de um jornalista ou profissional de letras para fazer resenha de livros, por exemplo, o grande questionamento que paira diz respeito à qualificação dos influenciadores para discorrer sobre a qualidade da obra ou sobre suas características técnicas. 0 crítico literário, historicamente autorizado a emitir juízos sobre livros dentro do campo literário, se vê diante da emergência de novos sujeitos mediadores, que, por sua vez, passam ao largo do predomínio da linguagem escrita. Para os seguidores, a qualificação do emissor da opinião pode não ser uma questão, mas o fato de os booktubers se tornarem visados por editoras influi na construção de laços de confiança: a opinião sobre uma obra é sincera e espontânea ou motivada e induzida por pagamento e/ou presente?

São conflitos de interesses muito característicos de uma era em que a comunicação ganha novos rumos. Onde não há divisões claras entre o produtor e o consumidor, entre o emissor e o receptor de mensagens. Cenário em que a comunicação é feita de muitos para muitos, de modo mais descentralizado, mesmo que se mantenham diversas estruturas de poder relacionadas. Essas dimensões estão não somente imbricadas, como justapostas. E a configuração contemporânea abala também as formas do fazer jornalístico e da crítica literária, permitindo a produção de conteúdo informacional por pessoas das mais variadas formações e saberes.

Por outro lado, os booktubers alegam que apenas transmitem suas opiniões e experiências, como leitores assíduos que são. E que isso já os qualificaria para

Dossiê Crise, Feminismo e Comunicação - https://revistaecopos.eco.ufrj.br/

ISSN $2175-8689$ - v. 23, n. 3, 2020

DOI: 10.29146/eco-pos.v23i3.27580 
exercer tal atividade. Eles reivindicam mais espaço em debates sobre literatura, como foi colocado no evento da Bienal do Livro de que participamos. Os três palestrantes ressaltaram a falta de prestígio desses produtores de conteúdo entre os organizadores de encontros sobre literatura e internet, como ocorria em muitos stands da própria Bienal, que não contavam com a presença de booktubers. Segundo eles, esses profissionais preferem chamar críticos renomados e pesquisadores e pouco convidam os que participam de um novo modo de compartilhamento de recomendações literárias.

São os booktubers os novos agentes culturais do campo literário (Paz, 2019), que intercedem direta e continuamente nos diferentes estágios desse circuito de comunicação. Afinal, selecionam os livros a serem indicados, produzem o cenário, roteirizam e editam seus vídeos e ainda interagem com o público nas redes. São figuras importantes no cenário literário, que interferem nos processos do mercado. Para a booktuber Bruna Miranda, a atuação deles está diretamente relacionada à vendagem de livros. Ela argumenta: “0 caminho das editoras é utilizar os booktubers para atingir o público jovem". Como muitos deles falam diretamente para essa parcela de internautas, existe uma influência considerável sobre o consumo de livros voltados para os jovens.

"Virou muito profissional! É o mercado de trabalho isso aqui!", comenta Beatriz Paludetto no vídeo "A Verdade sobre o Booktube com GeekFreak: Patrocínio, editoras e fofocas" 13 , referindo-se ao caráter por vezes mais "frio" que a rede booktube vem alcançando. Como ela é ampla e diversa, há estilos muito diferentes entre os booktubers: o conteúdo produzido atrai um público específico que se identifica com o influenciador. É uma construção da reputação, processo que leva ao reconhecimento e a maior visibilidade na rede, contribuindo também para a circulação de livros. Assim, a comunidade se guia em relações "de honestidade, transparência e confiança com seus seguidores" (Paz, 2019, p. 9).

13 Idem nota 4.

Dossiê Crise, Feminismo e Comunicação - https://revistaecopos.eco.ufrj.br/

ISSN 2175-8689 - v. 23, n. 3, 2020

DOI: 10.29146/eco-pos.v23i3.27580 
Há, nesse âmbito, uma condição distinta pela qual os livros circulam, dentro de um regime de valor em espaço e tempo específicos: é a "vida social" inerente a esses objetos (Appadurai, 2008), que se delineia a partir de ações humanas sobre eles - resultante do agenciamento dos booktubers e dos tensionamentos políticos relacionados em toda a comunidade. Os desejos e demandas comentados e ressaltados nos vídeos contribuem para gerar valor a essas mercadorias. As motivações e atribuições humanas dão significado aos objetos. Sendo assim, todo elogio aos livros presente nas discussões reverbera na valoração econômica deles.

Os booktubers são referências outras de leitura além da figura do crítico ou da escola. Essa experiência deve ser entendida a partir de encontros com os mais diversos textos que possibilitam transformações e interpretações plurais sobre o mundo. Trata-se de contribuir para a construção de diversas maneiras de pensar (Chartier, 1999). Com base nessa reflexão, a ideia de formação leitora como aquela propiciada pelas escolas se esfumaça. A atuação dos booktubers demonstra como esse processo tem o potencial de ocorrer de modo mais espontâneo e menos disciplinar, sem deixar de estar sujeito aos constrangimentos próprios da ordem capitalista.

\section{Considerações Finais}

As práticas de leitura contemporâneas são permeadas de múltiplos suportes, o que resulta na diversidade de apreensões do conteúdo lido e influencia na elaboração da subjetividade dos leitores. A figura do booktuber atua nesse cenário intensamente marcado pelas tecnologias de informação e comunicação que promovem o compartilhamento constante do íntimo. Interioridade e conexão praticamente incessante parecem não se coadunar em muitas análises sobre o capitalismo contemporâneo.

Contudo, destacamos que ler, conforme nos lembra Petit (2013), é construir um "quarto para si", pois permite a elaboração de um espaço próprio. Esse

\section{Dossiê Crise, Feminismo e Comunicação - https://revistaecopos.eco.ufri.br/}

ISSN $2175-8689$ - v. 23, n. 3, 2020

DOI: 10.29146/eco-pos.v23i3.27580 
processo é inerentemente relacional, pois um leitor nunca está "só" ou "isolado" se tomamos como referência sua necessária interação com um suporte, com um ou mais autores e com os universos criados por eles." (Almeida, 2020 p. 5) Essa relação propicia abertura para alteridade.

Na reflexão de Walter Benjamin, a interioridade diz respeito ao espaço onde as coleções são elaboradas. Os booktubers, por essa ótica, à primeira vista não falam a partir de um "invólucro" que os configuraria como colecionadores autênticos. Mas é preciso ter em conta que na reflexão benjaminiana as estratégias de aquisição das coisas e a transmissibilidade delas são relevantes. "Entre camadas oníricas e objetivas, portanto, a coleção é uma forma de acesso ao mundo a partir de um interior, mas nunca um encerramento nele." (Gomes, 2019).

Desse modo, a trincheira que o colecionador autêntico habita torna-se capilarizada quando abordamos os booktubers e o apreço pelos livros em papel. Por meio de suas bibliotecas em constante atualização, vislumbramos propósitos de coletividade e intercâmbio, mesmo dentro da lógica mercantil, em que os conteúdos disponíveis na internet inevitavelmente se inserem. São ações que envolvem construções de si e modos de olhar para o outro. Desejo de estar junto, online e offline.

Dados o fluxo comunicacional e a grande quantidade de possibilidades midiáticas, é normal que as referências proliferem. E elas são necessárias, muitas vezes. Para o leitor, ter uma indicação de leitura feita por alguém com quem ele se identifica e confia pode ser algo benéfico. Além disso, há também um desejo de pertencer a essa comunidade. Participar de eventos, interagir nas plataformas digitais, conhecer pessoas com os mesmos interesses, partilhar elogios à materialidade dos livros: sociabilidade muito comum e particular dessa comunidade de leitores altamente informatizados, ativos e diversos. 


\section{Referências bibliográficas}

ALMEIDA, Maria Isabel Mendes. O Desassossego do Leitor: Subjetividades Juvenis e Leitura na Contemporaneidade. Caderno IHU Ideias, Universidade do Vale do Rio dos Sinos, Instituto Humanitas Unisinos, no296, v. 18, 2020. Disponível em: http://www.ihu.unisinos.br/images/stories/cadernos/ideias/296cadernosihuidei as.pdf.

APPADURAI, Arjun. A vida social das coisas: As mercadorias sob uma perspectiva cultural. Niterói, RJ: Editora da Universidade Federal Fluminense, 2008.

BENJAMIN, Walter. Passagens. Belo Horizonte, MG: Editora da UFMG, 2006.

. Desempacotando minha Biblioteca: Um discurso sobre o colecionador. In: BENJAMIN, Walter. Rua de mão única. São Paulo, SP: Editora Brasiliense, 1987, p. 227-235.

CHARTIER, Roger. Ler sem livros. Palestra proferida na Universidade Candido Mendes - Unidade Centro, Rio de Janeiro - RJ, (17, set. 2018).

A aventura do livro: do leitor ao navegador. São Paulo, SP: Editora Unesp, 1999.

CRARY, Jonathan. 24/7: Capitalismo tardio e os fins do sono. São Paulo, SP: Cosac Naify, 2014.

DARNTON, Robert. A questão dos livros: Passado, presente e futuro. São Paulo, SP: Companhia das Letras, 1987.

DE CERTEAU, Michel. A Invenção do Cotidiano: volume 1. Artes de fazer. Petrópolis, RJ: Vozes, 2008.

ECO, Umberto; CARRIÈRE, Jean-Claude. Não contem com o fim do livro. Rio de Janeiro, RJ: Record, 2010. 
GARCÍA CANCLINI, Néstor. Leer en papel y en pantallas: el giro antropológico. In: GARCÍA CANCLINI, Néstor et al. Hacia una antropología de los lectores. Cidade do México \& Madri: Ediciones Culturales Paidós \& Fundación Telefónica, 2015, p. 138.

GELL, Alfred. A rede de Vogel, armadilhas como obras de arte e obras de arte como armadilhas. Arte e Ensaios - Revista do Programa de Pós- Graduação em Artes Visuais - Escola de Belas Artes, UFRJ, Rio de Janeiro, n. 8, 2001, p.175-191.

GOMES, Lilian Alves. Notas benjaminianas sobre aparição e interioridade de objetos de devoção em museus de arte do Rio de Janeiro. In: Camêlo, Lima, Bange e Souza. (Org.). Benjaminiana: outros escritos sobre arte, política, linguagem e história. 1ed.: Desalinho, 2019.

JEFFMAN, Tauana. Literatura compartilhada: uma análise da cultura participativa, consumo e conexões nos booktubers. Revista Brasileira de História da Mídia, v.4, n.2, p. 99-108, jul/dez. 2015.

JENKINS, Henry. Cultura da Convergência. São Paulo, SP: Aleph, 2008.

MCKENZIE, Donald F. Bibliography and the Sociology of Texts. Cambridge, UK: Cambrigde University Press, 2004.

PAZ, Eliane Hatherly. Um livro de cabeceira e uma câmera na mão: circulação e consumo literários na contemporaneidade. In: COMPÓS, 28., Porto Alegre, 2019. Anais eletrônicos... Porto Alegre: PUCRS, 2019.

PETIT, Michèle. Leituras: do espaço íntimo ao espaço público. São Paulo, SP: Editora 34, 2013.

PIC, Muriel. As Desordens da Biblioteca. Belo Horizonte, MG: Relicário, 2015.

SANTAELLA, Lucia. Navegar no ciberespaço: o perfil cognitivo do leitor imersivo. São Paulo, SP: Paulus, 2004.

Dossiê Crise, Feminismo e Comunicação - https://revistaecopos.eco.ufrj.br/

ISSN 2175-8689 - v. 23, n. 3, 2020

DOI: 10.29146/eco-pos.v23i3.27580 
SENNETT, Richard. O Declínio do Homem Público: as tiranias da intimidade. Tradução: Lygia Araújo Watanabe. São Paulo, SP: Companhia das Letras, 1999.

Juntos: os rituais, os prazeres e a política da cooperação. Tradução: Clóvis Marques. Rio de Janeiro, RJ: Record, 2012.

SHIRKY, Clay. A cultura da participação: criatividade e generosidade no mundo conectado. Rio de Janeiro, RJ: Zahar, 2011.

SIBILIA, Paula. O show do eu: a intimidade como espetáculo. Rio de Janeiro, RJ: Contraponto, 2016.

TOFFLER, Alvin. A Terceira onda. Rio de Janeiro, RJ: Record, 2007.

TURKLE, Sherry. Alone Together: Why We Expect More From Technology and Less From Each Other. New York, US: Basic Books, 2011. 